\title{
Uso do ultrassom point-of-care (POCUS) na parada cardiorrespiratória (PCR)
}

\author{
Use of point-of-care ultrasound (POCUS) in cardiorespiratory arrest (CRA)
}

Uso del ultrasonido de punto (POCUS) de atención en paro cardiorrespiratorio (PCR)

Ana Carolina Tassara Azevedo ${ }^{1}$, Igor de Souza Moreira ${ }^{1}$, Izabella Guedes Ferreira ${ }^{1}$, Johnny David Simões Madeira ${ }^{1 *}$, Rayanne Barros Spina ${ }^{1}$, Thais Avelar Caldeira Brant ${ }^{1}$, Eduardo Augusto dos Santos Moreira Silva ${ }^{1,2}$, Leonardo Arruda Moraes Raso ${ }^{1,2}$.

\section{RESUMO}

Objetivo: Explanar e discutir criticamente a importância do uso do ultrassom point-of-care (POCUS) na parada cardiorrespiratória (PCR), elucidando particularidades de sua utilização. Revisão Bibliográfica: A ocorrência de PCR apresentando-se como ritmo não chocável tem aumentado nas últimas décadas. É importante atualizar as formas de atender esses pacientes, para melhor prognóstico. O uso do POCUS nos atendimentos de PCR como ferramenta para diagnóstico e prognóstico para pacientes graves tem sido abordado nos protocolos. O uso do ultrassom pode ser considerado durante tais manobras, desde que não interfira no protocolo de ressuscitação cardiopulmonar. O POCUS pode ser utilizado principalmente para a identificação de causas reversíveis, mas há discussões sobre outras utilizações. Um argumento apresentado contra o uso do POCUS durante a PCR é que ele pode afetar adversamente a qualidade da ressuscitação cardiopulmonar. É essencial utilizar o ultrassom no momento correto e seguir rígidos protocolos. Exame físico e histórico permanecem fatores importantes na tomada de decisões, não devendo ser negligenciados. Considerações Finais: O exame mostrou-se útil para identificação de causas reversíveis de PCR, o que causa impacto no prognóstico. Além disso, mostrou outras aplicabilidades como identificação de falsos ritmos não chocáveis, avaliação da qualidade das compressões torácicas e parâmetro para cessação de esforços.

Palavras-chave: Ultrassonografia, Sistemas automatizados de assistência junto ao leito, Parada cardíaca.

\begin{abstract}
Objective: Explain and discuss critically the importance of POCUS use during CRA, elucidating the particularities of its usage. Bibliographic Review: The occurrence CRA presenting itself as a non-shockable rhythm has been rising in the last couple of decades. It is important to update the resources to attend these patients, aiming to improve prognosis. The use of POCUS as a tool for diagnosis and management has been addressed in the most recent advanced life support protocols. Its use can be considered during cardiopulmonary resuscitation (CPR), as long as it doesn't interfere with the resuscitation maneuvers. POCUS can be used mainly to identify reversible causes of CRA but there is discussion regarding other possibilities. A counter-argument about its use is that it may adversely affect the quality of the RPC. Physical examination and history still are important factors for decision making and should not be neglected. Final Considerations: POCUS is useful for identifying reversible causes of CRA which impacts prognosis. Furthermore, it has shown other possible uses, such as the identification of false non-shockable rhythms, the assessment of the quality of the chest compressions and as a parameter for ceasing resuscitation efforts.
\end{abstract}

Keywords: Ultrassonography, Point-of-care systems, Heart arrest.

\footnotetext{
${ }^{1}$ Pontifícia Universidade Católica de Minas Gerais (PUC Minas), Betim - MG.

*E-mail: johnny.jdsm@gmail.com

${ }^{2}$ Pontifícia Universidade Católica de Minas Gerais (PUC Minas), Contagem - MG.
} 


\section{RESUMEN}

Objetivo: Exponer y debatir críticamente acerca de la importancia de utilizar el POCUS en PCR, dilucidando las particularidades de su uso. Revisión Bibliográfica: la ocurrencia de un PCR de ritmo no desfibrilable ha aumentado en las décadas pasadas. Es importante actualizar las formas de atender a estos pacientes, para mejor pronóstico. El uso del POCUS como herramienta para diagnóstico y manejo se ha abordado en los protocolos de soporte vital avanzado más recientes. Puede considerarse el uso de ultrasonido durante la reanimación cardiopulmonar (RCP) si no interfiere con tales maniobras. POCUS puede usarse principalmente para identificar causas reversibles de PCR, pero hay discusiones acerca de otros usos. Un argumento en contra del uso de POCUS durante el PCR es que puede afectar negativamente la calidad de la RCP. Es esencial utilizar el ultrasonido en el momento adecuado y seguir protocolos estrictos. El examen e histórico siguen siendo factores importantes en la toma de decisiones y no deben ser descuidados. Consideraciones Finales: POCUS es útil para identificar causas reversibles de PCR que impacta el pronóstico. Además, mostró otras aplicabilidades como la identificación de falsos ritmos no desfibrilables, evaluación de la calidad de las compresiones torácicas y parámetro de cesación de esfuerzos.

Palabras clave: Ultrasonografía, Sistemas de atención de punto, Paro cardíaco.

\section{INTRODUÇÃO}

A parada cardíaca é um dos principais desencadeadores de mortalidade e invalidez em todo o mundo (HUSSEIN L, et al., 2019). Ela se configura como uma das mais importantes causas de morte e morbidade, no Brasil e no mundo. Embora os serviços de emergência tenham feito grandes esforços de ressuscitação cardiopulmonar (RCP), as taxas de sobrevivência permanecem baixas.

Grande parte do tempo de uma RCP, de acordo com Hussein L, et al. (2019), é despendido repetindo ações iniciais ou simplesmente esperando o próximo acontecimento, que muitas vezes pode ser o óbito. Dados da American Heart Association apontam uma taxa de sobrevivência geral após alta hospitalar de cerca de $10 \%$ no que se refere a parada extra-hospitalar, e de menos de $25 \%$, em parada intra-hospitalar (GO AS, et al., 2013).

O ultrassom point-of-care (POCUS), utilizado no ponto de atendimento, demonstra dados fisiológicos em tempo real, possibilitando refletir mudanças dinâmicas ocorridas em função de tratamentos médicos (KEDAN I, et al., 2020). Ademais, essa tecnologia pode oferecer informações quanto ao prognóstico de pacientes com comorbidades como insuficiência cardíaca e fibrilação atrial.

Neste caso, o POCUS pode ser utilizado tanto para diagnosticar etiologicamente quanto para fazer prognósticos dos resultados da RCP. Por fim, o ultrassom também demonstrou ser útil na análise de presença de causas reversíveis de parada cardíaca, e diversos estudos clínicos ponderam o uso do movimento cardíaco, visualizado com a tecnologia do ultrassom no local do atendimento, como um preditor de resultados em pacientes com parada cardíaca (KEDAN I, et al., 2020).

Dados dos últimos 30 anos, apontam que o POCUS geralmente adota um valor prognóstico expressivo ao exame clínico, especialmente quanto ao retorno à circulação espontânea (RCE). Eles relatam que o uso de exame de imagens durante a RCP é descrito desde meados de 1980.

E que, na época, o ecocardiograma transesofágico foi utilizado pela primeira vez na investigação de causas reversíveis de parada cardiorrespiratória (PCR). A partir daí seu uso se disseminou significativamente, tornando-se popular em vários países (HUSSEIN L, et al., 2019).

Já na última década, a Sociedade Americana de Ecocardiografia e o Colégio Americano de Médicos de Emergência constituíram um consenso a respeito das atribuições do ultrassom nas emergências cardiovasculares (HUSSEIN L, et al., 2019).

No que se refere à PCR, ele pode auxiliar na distinção do ritmo cardíaco organizado da assistolia, e da atividade elétrica sem pulso (AESP) verdadeira da falsa, na identificação de causas reversíveis de parada, e na condução de procedimentos de RCP e de RCE. 
Outrossim, a Sociedade Europeia de Cardiologia reconheceu o ultrassom como meio de aperfeiçoar o diagnóstico e guiar os cuidados agudos em pacientes em PCR. Ademais, as diretrizes de ressuscitação europeia de 2015 também corroboraram intensamente com uso do POCUS, que foi incorporado ao Advanced Cardiovascular Life Support (ACLS), e em 2017 foram aprovadas diretrizes quanto ao uso de ecocardiograma transesofágico na parada cardíaca (HUSSEIN L, et al., 2019).

Dessa forma, pode-se afirmar que o POCUS tem se configurado como uma ferramenta valiosa para os serviços de saúde, especialmente para os departamentos de urgência e emergência. Assim, este trabalho visa a explanar e discutir a importância do seu uso durante a PCR, de forma crítica. Além disso, elucidar quanto às utilidades para diagnósticos, prognósticos, aspectos técnicos e práticos, protocolos e premissas básicas para a sua utilização.

\section{REVISÃO BIBLIOGRÁFICA}

Ao longo das últimas décadas, vem existindo uma tendência de diminuição da ocorrência de PCR apresentando-se como ritmos chocáveis (fibrilação ventricular e taquicardia ventricular) e aumento da ocorrência dos ritmos não chocáveis (assistolia e AESP) (TEODORESCU C, et al., 2010). Esse é um dado importante visto que a taxa de sobrevivência em casos de AESP chega a ser $6 \%$, comparada a $40 \%$ nos casos de fibrilação ventricular e taquicardia ventricular, em que a desfibrilação é o foco do tratamento (ENGDAHL J, et al., 2001; GREENE HL, 1990).

Dessa forma é importante que existam novas formas de atender ao paciente em PCR com ritmo não chocável, visando ao melhor prognóstico. É reconhecido que o suporte avançado à vida é essencial na cadeia de sobrevivência em situações de paradas cardíacas, e a criação de protocolos e algoritmos torna possível que a assistência médica se organize, oferecendo de forma sistematizada as melhores condutas evidenciadas pela literatura mais recente.

Desde 2005, o ACLS da American Heart Association orienta a busca de causas reversíveis, principalmente na ocorrência de ritmos não chocáveis, quando a desfibrilação não é indicada e a continuidade das manobras de ressuscitação é a única conduta possível. À atualização do ACLS de 2015, Mark SLF, et al. (2015) aborda sobre o uso do POCUS, nos atendimentos de PCR, como ferramenta para diagnóstico e prognóstico de pacientes em estado crítico. Essas recomendações descrevem que o uso do ultrassom pode ser considerado durante o manejo da PCR, embora seja importante que ele não interfira no protocolo de RCP.

Segundo Mark SLF, et al. (2015) o uso do ultrassom é relevante para avaliar a função cardíaca (contração miocárdica) e para tratar causas potencialmente associadas à PCR como hipovolemia, pneumotórax, tromboembolismo pulmonar e tamponamento cardíaco, afirmando, contudo, que seu uso rotineiro e seus benefícios clínicos ainda não são tão contundentes (SOAR J, et al., 2015). Mais recentemente, em 2017, foi estabelecido um consenso internacional pela Federação internacional de medicina de emergência sobre 0 uso do ultrassom em pacientes com hipotensão indiferenciada e parada cardíaca.

O consenso foi coordenado por especialistas na área de medicina intensiva, em que foi formulado um protocolo para hipotensão e parada cardíaca. Nesta resolução foram selecionadas as regiões a serem vistas pelo ultrassom durante $O$ atendimento de forma a não interferir ou minimizar as compressões torácicas. No entanto, esse consenso ainda espera uma validação (ATKINSON P, et al., 2017). Apesar de o foco principal da utilização do POCUS durante a RCP ser a identificação de causas reversíveis, existem outras possibilidades do seu uso que, ainda que não sejam abordadas, apresentam grande potencial e importância.

Uma delas, por exemplo, está relacionada com o tratamento de algumas dessas causas, como a pericardiocentese, que pode ser facilitada quando o ultrassom é utilizado como guia (BLANCO P e BUENDÍA CM, 2017). Ainda segundo Blanco P e Buendia MC (2017), causas reversíveis não são as únicas que podem ser detectadas com o uso do POCUS, uma vez que também pode ser aplicado para diagnóstico de valvopatias severas, disfunção sistólica de ventrículo direito (VD) ou de ventrículo esquerdo (VE) e ruptura cardíaca que podem estar associadas. 
Além do enfoque nas causas de PCR e seus tratamentos, ainda há discussão sobre a utilização do POCUS com outros objetivos, como a distinção entre assistolia verdadeira da falsa assistolia. Há relatos de casos em que havia aparente assistolia no monitor, mas, ao realizar a ultrassonografia, foi identificada uma fibrilação ventricular fina (AMAYA SC e LANGSAM A, 1999; LIMB C e SIDDIQUI MA, 2015).

Há estudos que evidenciam que esse mascaramento da fibrilação ventricular não é comum, mas ocorre em 8 a 9\% dos casos de assistolia após correção de problemas técnicos (AUSTIN D, et al., 1998). Assim, apesar de rara, a identificação dessa ocorrência é muito importante, uma vez que a conduta mudará para esses pacientes, visto que a fibrilação ventricular é um ritmo chocável, o que melhora seu prognóstico.

Outra possibilidade seria como um possível preditor para interrupção dos esforços de ressuscitação, como no estudo feito por Blaives M e Fox JC (2001). Os resultados desse estudo mostraram que todos os pacientes que foram submetidos ao ecocardiograma de cabeceira, independente do ritmo que apresentavam, não sobreviveram quando a ultrassonografia revelava ausência de movimentos cardíacos.

Uma revisão sistemática realizada por Blyth $\mathrm{L}$, et al. (2012) também mostrou forte relação entre ausência de movimentos cardíacos e não ocorrência do retorno à circulação espontânea (RCE), levando a mortalidade. Cerca de 84 a 96\% dos pacientes que cursaram com RCE possuíam atividade cinética cardíaca ao ultrassom. Porém, alguns pacientes apresentavam RCE, mesmo com ausência de atividade cinética. Logo, é possível inferir que o ultrassom pode ser um dos prenunciadores da interrupção das manobras no atendimento à PCR, mas não deve ser o único parâmetro a ser avaliado ao tomar a decisão de cessar ou não os esforços.

Ademais, segundo os autores Blanco P e Buendia MC (2017) o POCUS poderia também verificar a efetividade das compressões torácicas, mostrando em tempo real a contração e o relaxamento das câmaras cardíacas quando aplicadas as compressões. Para esse uso, especificamente, seria necessário o uso da ecocardiografia transesofágica, que permite a realização do exame enquanto as compressões estão sendo feitas, ao contrário da ecocardiografia transtorácica (BLAIVAS M, 2008).

As compressões torácicas de alta qualidade são um componente crítico da ressuscitação dos pacientes em parada cardiopulmonar. E um argumento apresentado contra o uso do POCUS durante a PCR é que ele afeta adversamente a qualidade da RCP, por prolongar a duração das verificações de pulso, que deve ser até dez segundos, conforme as diretrizes de reanimação (HUIS IN 'T VELD MA, et al., 2017). Em contrapartida, outro estudo, de Flato UAP, et al. (2015), mostrou que a realização da ecocardiografia transtorácica, durante a ressuscitação desses pacientes, foi viável e produziu imagens de boa qualidade em intervalos tão curtos quanto os intervalos de dez segundos estabelecidos nos protocolos.

Contudo, para que isso seja possível, é essencial que os prestadores de cuidados prestem atenção à duração das interrupções da RCP ao usar POCUS durante a ressuscitação na parada cardíaca, sendo de suma importância seguir rígidos protocolos de uso, para não interferir negativamente no atendimento do paciente.

Esse ponto leva a outro questionamento, sobre a capacitação do operador, visto que, além da agilidade necessária para não atrapalhar as compressões, a ultrassonografia é um exame cuja interpretação e diagnóstico é operador-dependente. Não obstante, o uso do POCUS, segundo uma pesquisa realizada por Price S, et al. (2010), mostrou que até mesmo médicos minimamente treinados podem ser capazes de diagnosticar causas reversíveis de PCR, por meio desse método de imagem. A mesma pesquisa mostrou que a interpretação e o tempo de conclusão do diagnóstico apresentaram melhor eficiência após o oferecimento de cursos feitos até mesmo em um único dia.

Outro aspecto fundamental para que a utilização do POCUS não seja iatrogênica, é a qualidade e as características do aparelho, além do momento correto para sua utilização. É ideal que o aparelho de ultrassom tenha inicialização e configurações rápidas, seja portátil e que seja usado com um único transdutor, o qual seja capaz de avaliar diversas áreas, ou, ainda, com no máximo dois transdutores, desde que a troca entre eles seja ligeira (BLANCO P e BUENDÍA CM, 2017). Ademais, Soar J, et al. (2015) trazem, nas diretrizes europeias sobre ACLS, recomendações de que o transdutor seja posicionado em região abaixo do xifoide, pouco antes das compressões serem pausadas para checagem planejada de ritmo, possibilitando que 0 examinador obtenha visualização em dez segundos. 
Outro aspecto que contribui para o bom aproveitamento do POCUS é a instauração de protocolos para seu uso nos centros de atendimento. Aqui ressalta-se a implementação e o uso sistemático do protocolo Cardiac Arrest Ultrasound Exam (CAUSE) (HERNANDEZ C, et al., 2008). O protocolo serve para organizar um processo que às vezes pode ser caótico e desorganizado. E, segundo estudos anteriores, o aumento da organização durante a ressuscitação aumenta a probabilidade de sobrevivência (FLATO UAP, et al., 2015). O protocolo CAUSE aborda quatro das principais causas de doenças cardíacas: hipovolemia, tamponamento cardíaco, embolia pulmonar e pneumotórax. Isso é possível, pois são usadas duas perspectivas sonográficas do tórax, a saber: uma visão das quatro câmaras cardíacas e do pericárdio, e outra ântero medial do pulmão e da pleura, no nível do segundo espaço intercostal e linha médio clavicular bilateralmente.

Segundo Hernandez C, et al. (2008), os pacientes são tratados com protocolo de ressuscitação padrão. Depois que o monitor é conectado, os pacientes são divididos em dois grupos: arritmogênico (ou seja, fibrilação ventricular e taquicardia ventricular) e não arritmogênica (assistolia e AESP). Pacientes arritmogênicos são tratados com cardioversão, mas pacientes não arritmogênicos são examinados com o Protocolo CAUSE para excluir prontamente causas reversíveis para a cessação da circulação. Existem outros protocolos além do CAUSE, como o FEEL e o PEA, sendo que a principal diferença entre eles são os órgãos avaliados (BREITKREUTZ R, et al., 2007; TESTA A, et al., 2010). O CAUSE, como abordado, examina coração e pulmões, o FEEL avalia apenas o coração, e o PEA é multi-órgão, avalia além de coração e pulmões, abdome e veias profundas proximais dos membros inferiores (BLANCO B e BUENDÍA CM, 2017).

Ao exame ultrassonográfico, durante a PCR, a visão cardíaca é a primeira realizada, pois fornece potencial para diagnosticar uma das três condições (embolia pulmonar maciça, tamponamento cardíaco e hipovolemia), e essa visão leva menos tempo, o que significa menos interferência com a reanimação (HERNANDEZ C, et al., 2008). A partir de então, é feita a busca por algumas das principais condições que poderiam estar causando a PCR, como hipovolemia, pneumotórax hipertensivo, embolia pulmonar e tamponamento cardíaco, além de insuficiência cardíaca. Nesse sentido, a hipovolemia é caracterizada por uma redução do volume intravascular. As causas da hipovolemia incluem hemorragias, diarreias, vômitos e sepse. Esta condição pode levar o indivíduo à morte quando é desencadeado o choque hipovolêmico, que acarreta em consequências sistêmicas mais graves.

Os sintomas apresentados podem ser: má perfusão periférica, taquicardia, oligúria, hipotensão, taquipneia e alteração do estado mental. Os achados diagnósticos por imagem pelo POCUS são câmaras cardíacas esvaziadas, uma veia cava inferior plana, efusões peritoneais e pleurais, e uma possível ruptura da aorta abdominal. Além disso, observou-se que o volume diastólico final do VE se correlacionou extremamente bem com a perda de sangue. Assim, pode-se detectar pequenas alterações no sistema intravascular, o que demonstra que os ultrassons são ferramentas úteis para determinação do status do volume (HERNANDEZ C, et al., 2008).

O tratamento indicado é a reposição volêmica por hemoderivados ou cristaloides, mantendo a RCP (MALBRAIN M, et al., 2018). É importante considerar que algumas condições clínicas podem não ter essa relação linear entre o achatamento da veia cava inferior e a condição do volume, como embolia pulmonar maciça, hipertensão intra-abdominal e ventilação mecânica com pressões positivas (BLANCO P. e VOLPICELLI G, 2016).

Já o pneumotórax hipertensivo, é definido como a presença de ar no espaço pleural, e são associados a episódios de traumas ou de iatrogenias. Este pode ser primário ou espontâneo, sem doença ou fator precipitante, ou secundário a doença pulmonar preexistente e trauma. As manifestações clínicas são dor torácica aguda, dispneia e presença de murmúrio vesicular assimétrico.

Os achados diagnósticos através do POCUS são câmaras cardíacas com seu conteúdo reduzido, sinal deslizante do movimento da pleura visceral ao longo da pleura parietal, quando vista anteromedialmente ao nível do segundo espaço intercostal e linha média clavicular, e veia cava inferior dilatada. É importante considerar que o pneumomediastino pode mimetizar um pneumotórax esquerdo (BLANCO P e VOLPICELLI G, 2016). O tratamento é realizado por uma toracocentese de alívio, no quinto espaço intercostal na linha axilar média, sem interrupção da RCP, e posteriormente uma toracotomia no mesmo local (NEUDECKER J, et al., 2014; HERNANDEZ C, et al., 2008). 
A embolia pulmonar é causada por uma obstrução de uma artéria do pulmão pelo acúmulo de material sólido trazido através da corrente sanguínea (êmbolo). Ela é a causa de $5 \%$ das paradas cardíacas sendo a AESP diagnosticada em $63 \%$ e assistolia em outros $32 \%$ dos nesses casos, segundo (HERNANDEZ C, et al., 2007).

As principais medidas hospitalares de tratamento são a administração de oxigênio, de analgésicos para controle da dor e de anticoagulantes para evitar a progressão dos coágulos existentes e impedir a formação de novos. Portanto, o ultrassom parece ser um excelente teste de cabeceira para detectar a presença de grandes êmbolos pulmonares capazes de causar parada cardíaca.

Em alguns casos pode ser difícil a constatação da dilatação de VD, uma vez que ela depende da boa visualização tanto do VD, quanto do VE, para que seja feita a comparação entre eles. Além disso, outras condições podem causar dilatação de VD, como a hipertensão pulmonar crônica e a regurgitação crônica de valvas tricúspide ou pulmonar (BLANCO P e VOLPICELLI G, 2016).

O tamponamento cardíaco ocorre devido ao aumento da pressão intrapericárdica, causada pela presença de aumento de líquido ou gás no espaço pericárdico. Seu diagnóstico é essencialmente clínico, mas o ECG e a ecocardiografia podem ser feitos.

O ultrassom no diagnóstico de tamponamento cardíaco é amplamente aceito e usado. Ele acrescenta maior nível de precisão para a determinação da causa de parada cardíaca e pode impedir o uso de terapia inadequada.

Entretanto, o exame físico e a história clínica permanecem fatores importantes na tomada de decisões médicas, e sua importância não deve ser negligenciada. Além disso, em ultrassonografias podemos encontrar câmaras cardíacas vazias (VD e VE achatados nas vistas subxifoide ou eixo longo do coração) e veia cava inferior pletórica.

Se visualizado efusão, é importante fazer o diagnóstico diferencial entre efusão pericárdica, efusão pleural, ascite e tecido gorduroso. A efusão pericárdica normalmente é anterior à aorta descendente, já a pleural, no ultrassom cardíaco, é posterior ou lateral à aorta descendente.

A ascite é mais presente em janelas subcostais, anteriormente às câmaras cardíacas direitas e, nesse caso, também será possível visualizar ligamento falciforme no líquido e movimento visível de diafragma. Já a gordura epicárdica e/ou mediastinal é melhor visualizada em janelas paraesternais durante a sístole (BLANCO P e VOLPICELLI G, 2016). Nesses casos, é interessante a realização do ultrassom pulmonar e abdominal para confirmação.

O tamponamento cardíaco caracteriza-se como uma emergência clínica, sendo necessário um tratamento cirúrgico, através de uma toracotomia ou esternotomia, e recomenda-se uma pericardiocentese para descompressão temporária em pacientes instáveis (BARRA LD, et al., 2008).

A insuficiência Cardíaca (IC), seja ela de VE ou VD, pode ser definida como uma síndrome complexa que resulta na incapacidade do coração em bombear o sangue de forma eficiente para atender as necessidades metabólicas, ou demanda que o órgão precise de altas pressões para realizar tal feito.

Ela pode ser causada por alterações estruturais, incluindo disfunções ou acometimentos valvares ou funcionais, e se apresenta com sintomatologia típica de baixo débito cardíaco ou de altas pressões de enchimento.

A IC pode ser crônica ou aguda, dependendo do tempo e progressão da patologia. A IC aguda é, atualmente, uma das principais causas de internação hospitalar, e configura aproximadamente 190 mil internações no Brasil.

O ultrassom é uma das principais formas de auxílio diagnóstico das Insuficiências cardíacas, principalmente se utilizado em associação ao método Doppler (ROHDE LEP, et al., 2018). Os achados do exame ultrassonográfico de cada uma das principais possíveis causas de PCR estão resumidas abaixo e incluem a hipovolemia, pneumotórax hipertensivo, embolia pulmonar, tamponamento cardíaco e insuficiência de VE ou VD, além de acometimento valvar agudo (KEDAN I, et al., 2020) (Quadro 1). 
Quadro 1 - Correlação entre causas de PCR e possíveis achados ultrassonográficos.

\begin{tabular}{|c|c|c|c|}
\hline \multirow{2}{*}{$\begin{array}{c}\text { Causas de PCR } \\
\text { elegíveis }\end{array}$} & \multicolumn{3}{|c|}{ Achados do POCUS } \\
\hline & Cardíaco & Pulmonar & Abdominal \\
\hline Hipovolemia & $\begin{array}{l}\text { V. Cava inferior achatada; } \\
\text { Câmaras cardíacas } \\
\text { "vazias" }\end{array}$ & Efusão pleural; & $\begin{array}{l}\text { Ruptura de a. Aorta } \\
\text { abdominal; Efusão } \\
\text { peritoneal; }\end{array}$ \\
\hline $\begin{array}{l}\text { Pneumotórax } \\
\text { Hipertensivo }\end{array}$ & $\begin{array}{l}\text { Câmaras cardíacas } \\
\text { "vazias"; V. Cava inferior } \\
\text { pletórica }\end{array}$ & $\begin{array}{l}\text { Perfil } A^{*} \text { (sem deslizar em } \\
\text { tempo real) }\end{array}$ & $\ldots$ \\
\hline Embolia Pulmonar & $\begin{array}{l}\text { VD dilatado; V. Cava } \\
\text { inferior pletórica }\end{array}$ & X & $\mathrm{X}_{-}$ \\
\hline $\begin{array}{l}\text { Tamponamento } \\
\text { Cardíaco }\end{array}$ & $\begin{array}{l}\text { Câmaras cardíacas } \\
\text { "vazias" + Efusão } \\
\text { pericárdica; V. Cava } \\
\text { inferior pletórica }\end{array}$ & X & $x_{-}$ \\
\hline Insuficiência de VE & Contração pobre em VE & Perfil B** & $\mathrm{X}$ \\
\hline Insuficiência de VD & VD dilatado & Perfil A* (pulmão seco) & X \\
\hline $\begin{array}{l}\text { Acometimento } \\
\text { Valvar Agudo }\end{array}$ & $\begin{array}{l}\text { Contração hiperdinâmica } \\
\text { de VE; Ruptura de m. } \\
\text { papilar }\end{array}$ & Perfil B** & $\mathrm{X}$ \\
\hline
\end{tabular}

Legenda: *Perfil A: linhas horizontais brancas (hiperecogênicas) que são estáticas e aparecem em intervalos regulares **Perfil $B$ : artefatos verticais hiperecogênicos que se movem em sincronia com o ciclo respiratório.

Fonte: Azevedo ACT, et al., 2020.

Na embolia pulmonar, assim como na insuficiência de VD, o rastreamento em veias profundas de membro inferior pode ser associado ao POCUS, a evidenciar sinais de trombose (BLANCO B e BUENDÍA CM, 2017). $\mathrm{Na}$ literatura, existem relatos de casos em que o uso do POCUS foi fundamental para a identificação de causas reversíveis da PCR, de maneira a possibilitar sua correção e salvar a vida do paciente (STEIGER HV, et al., 2009; HOLLON MM, et al., 2019).

Existem estudos prospectivos os quais mostram que o uso do POCUS de fato reduziu a mortalidade desses pacientes, outros apontam que, apesar de identificar as causas reversíveis, não houve impacto na mortalidade (ATKINSON PR, et al., 2019; CHARDOLI M, et al., 2012). Entretanto, existem duas metanálises, dentro do conhecimento dos autores, que avaliaram o prognóstico em PCR não traumática, com ritmos não chocáveis.

Uma delas mostrou um significativo aumento nas chances de retorno à circulação espontânea (RCE) com o uso do POCUS e a outra, além da RCE, evidenciou também aumento nas chances de sobrevivência à internação hospitalar e à alta hospitalar. Essas pesquisas, contudo, apresentam algumas limitações visto que o número de estudos elegíveis foi pequeno e havia relativa heterogeneidade entre eles (WU C, et al., 2018; TSOU PY, et al., 2017).

\section{CONSIDERAÇÕES FINAIS}

A realização desse estudo permitiu a elucidação de diversos pontos sobre o uso do POCUS no contexto de ressuscitação da PCR. Esse exame, quando realizado de forma correta por profissionais treinados, seguindo protocolos, mostrou-se útil para a identificação de causas reversíveis da PCR. O impacto disso em um bom prognóstico, com diminuição da mortalidade, ainda é debatido, embora a literatura mais recente tenda a indicar que esse impacto de fato existe. Como ainda são poucos os estudos realizados nessa área, é necessária uma pesquisa mais extensa para que sejam conhecidas todas as potenciais aplicabilidades do POCUS, incluindo identificação de falsos ritmos não chocáveis, avaliação da qualidade das compressões torácicas, parâmetro para cessação de esforços, além da identificação de causas reversíveis. 


\section{REFERÊNCIAS}

1. AMAYA SC, LANGSAM, A. Detecção por ultrassom da fibrilação ventricular disfarçada de assistolia. Annals Of Emergency Medicine An International Journal, 1999; 33(3): 344-346.

2. ATKINSON P. International Federation for Emergency Medicine Consensus Statement: Sonography in hypotension and cardiac arrest (SHoC): An international consensus on the use of point of care ultrasound for undifferentiated hypotension and during cardiac arrest. Canadian Journal of Medicine, 2017; 19(6): 459-470.

3. ATKINSON PR. Does Point-of-care Ultrasound Use Impact Resuscitation Length, Rates of Intervention, and Clinical Outcomes During Cardiac Arrest? A Study from the Sonography in Hypotension and Cardiac Arrest in the Emergency Department (SHoC-ED) Investigators. Cureus, 2019; 11(4): 1-9.

4. AUSTIN D. The frequency of 'Occult' ventricular fibrillation masquerading as a flat line in prehospital cardiac arrest. Elsevier, 1998; 17(8): 813-817.

5. BARRA LD, et al. Tamponamento cardíaco agudo: uma breve revisão. Revista médica de Minas Gerais. 2008; 18(4): S37-S40.

6. BLAIVES M, FOX JC. Outcome in Cardiac Arrest Patients Found to Have Cardiac Standstill on the Bedside Emergency Department Echocardiogram. Official Journal of The Academic Emergency Medicine, 2008; 8(6): 612621.

7. BLAIVAS M. Transesophageal echocardiography during cardiopulmonary arrest in the emergency department. Resuscitation, 2008; 78(2): 135-140.

8. BLANCO P, BUENDÍA MC. Point-of-care ultrasound in cardiopulmonary resuscitation: a concise review. Società Italiana di Ultrasonologia in Medicina e Biologia (SIUMB), 2017; 20 (3): 193-198.

9. BLANCO P, VOLPICELLI G. Common pitfalls in point-of-care ultrasound: a practical guide for emergency and critical care physicians. Critical Ultrasound Journal, 2016;8(1):15-27.

10. BLYTH L, et al. Bedside focused echocardiography as predictor of survival in cardiac arrest patients: a systematic review [published correction appears in Acad Emerg Med. 2015 Jul;22(7):892. Acad Emerg Med., 2012;19(10): 11191126.

11. BREITKREUTZ $R$, et al. Focused echocardiographic evaluation in resuscitation management: Concept of an advanced life support-conformed algorithm. Society of Critical Care Medicine and Lippincott Williams \& Wilkins, 2007; v. $35(5): 150-161$.

12. CHARDOLI M, et al. Echocardiography integrated ACLS protocol versus conventional cardiopulmonary resuscitation in patients with pulseless electrical activity cardiac arrest. Chin J Traumatol,. 2012;15(5):284-287.

13. ENGDAHL J, et al. Factors affecting short- and long-term prognosis among 1069 patients with out-of-hospital cardiac arrest and pulseless electrical activity. Resuscitation, 2001; 51 (1):17-25.

14. FLATO UAP, et al. Echocardiography for prognostication during the resuscitation of intensive care unit patients with non-shockable rhythm cardiac arrest. Clinical paper, 2015; 92:1-6.

15. GO AS et al. Heart Disease and Stroke Statistics - 2013 Update. Circulation, 2013; 127(1): 6-245.

16. GREENE HL. Sudden arrhythmic cardiac death: mechanisms, resuscitation and classification: the Seattle perspective. Am J Cardiol., 1990; 65:4B-12B.

17. HERNANDEZ C, et al. C.A.U.S.E.: Cardiac arrest ultra-sound exam-A better approach to managing patients in primary non-arrhythmogenic cardiac arrest. Clinical paper, 2008; 76 (2):198-206.

18. HOLLON MM, et al. A Case Report Describing the Use of Point of Care Ultrasound to Guide Successful Cardiopulmonary Resuscitation After Unanticipated Arrest in Ambulatory Surgery. A Pract, 2019; 12(10): 359-361.

19. HUIS IN 'T VELD MA, et al. Ultrasound use during cardiopulmonary resuscitation is associated with delays in chest compressions. Revista Resuscitation, 2017; 119:95-98.

20. HUSSEIN L, et al. Bedside ultrasound in cardiac standstill: a clinical review. The Ultrasound Journal, $2019 ; 11$ (1): $11-35$.

21. KEDAN I, et al. Prognostic value of point-of-care ultrasound during cardiac arrest: a systematic review. Cardiovascular Ultrasound, 2020; 18(1): 1-10.

22. LIMB C, SIDDIQUI MA. Apparent Asystole: Are We Missing a Lifesaving Opportunity? Bmj Journals, 2015.

23. MALBRAIN M, et al. Assessment of hypovolemia in the critically ill: Anaesthesiology Intensive Therapy, 2018; 50:150159.

24. MARK SLF. American Heart Association guidelines for Cardiopulmonary Resuscitation and Emergency Cardiovascular Care Circulation, 2005; 112(24): 1-230.

25. NETO FLD, et al. Acurácia diagnóstica do protocolo de ultrassom pulmonar à beira do leito em situações de emergência para diagnóstico de insuficiência respiratória aguda em pacientes com ventilação espontânea. J. bras. pneumol., São Paulo, 2015; 41(1):58-64.

26. NEUDECKER J, et al., Pneumothorax: Willkomen bei Thieme E-book and journals, 2014; 139: 69-87.

27. PRICE S, et al. Peri-resuscitation Echocardiograpy: Traning the Novice Practitioner. NationalLibrary of Medicine, 2010; $81(11): 1534-9$.

28. ROHDE LEP, et al. Diretriz Brasileira de Insuficiência Cardíaca Crônica e Aguda,2018,111(3): 436-539.

29. SOAR J, et al. European Resuscitation Council Guidelines for Resuscitation, 2015: Section 3. Adult advanced life support. Resuscitation, 2015; 95:100-147.

30. STEIGER HV, et al. Focused emergency echocardiography: lifesaving tool for a 14-year-old girl suffering out-ofhospital pulseless electrical activity arrest because of cardiac tamponade. Eur J Emerg Med., 2009;16(2):103-105.

31. TEODORESCU C, et al. Factors associated with pulseless electric activity versus ventricular fibrillation: the Oregon sudden unexpected death study. Circulation, 2010; 122(21): 2116-2122.

32. TESTA A, et al. The proposal of an integrated ultrasonographic approach into the ALS algorithm for cardiac arrest: the PEA protocol. Eur Rev Med Pharmacol Scli, 2010; 14(2):77-88.

33. TSOU PY, et al. Accuracy of point-of-care focused echocardiography in predicting outcome of resuscitation in cardiac arrest patients: A systematic review and meta-analysis. Resuscitation, 2017; 114:92-99.

34. WU C, et al. The predictive value of bedside ultrasound to restore spontaneous circulation in patients with pulseless electrical activity: A systematic review and meta-analysis. PLoS One, 2018; 13(1). 